\title{
Cytokine gene polymorphisms in preterm infants with necrotising enterocolitis: genetic association study
}

G Henderson, S Craig, R J Baier, N Helps, P Brocklehurst and W McGuire

Arch. Dis. Child. Fetal Neonatal Ed. 2009;94;F124-F128; originally published online 3 Sep 2007;

doi:10.1136/adc.2007.119933

Updated information and services can be found at:

http://fn.bmj.com/cgi/content/full/94/2/F124

These include:

References This article cites 29 articles, 10 of which can be accessed free at: http://fn.bmj.com/cgi/content/full/94/2/F124\#BIBL

Rapid responses You can respond to this article at: http://fn.bmj.com/cgi/eletter-submit/94/2/F124

Email alerting Receive free email alerts when new articles cite this article - sign up in the box at service the top right corner of the article

Notes

To order reprints of this article go to:

http://journals.bmj.com/cgi/reprintform

To subscribe to Archives of Disease in Childhood - Fetal and Neonatal Edition go to:

http:/journals.bmj.com/subscriptions/ 


\title{
Cytokine gene polymorphisms in preterm infants with necrotising enterocolitis: genetic association study
}

\author{
G Henderson, ${ }^{1}$ S Craig, ${ }^{2}$ R J Baier, ${ }^{3}$ N Helps, ${ }^{4}$ P Brocklehurst, ${ }^{5}$ W McGuire ${ }^{6}$
}

- Additional data are published online only at http://adc.bmj. com/content/vol94/issue2

${ }^{1}$ Department of Health Sciences, Griffith University, Brisbane, Australia; ${ }^{2}$ Regional Neonatal Unit, Royal Jubilee Maternity Hospital, Belfast, UK;

${ }^{3}$ Department of Paediatrics,

University of Manitoba, Canada;

${ }^{4}$ The Sequencing Service,

College of Life Sciences,

University of Dundee, UK;

${ }^{5}$ National Perinatal Epidemiology

Unit, University of Oxford, UK;

${ }^{6}$ Centre for Newborn Care,

Australian National University,

Canberra, Australia

Correspondence to:

Dr W McGuire, Centre for

Newborn Care, The Canberra

Hospital, ACT 2606, Australia;

william.mcguire@act.gov.au

Accepted 13 August 2007

Published Online First

8 November 2007

\section{ABSTRACT}

Background: The inflammatory cytokine cascade is implicated in the pathogenesis of necrotising enterocolitis (NEC). Genetic association studies of cytokine polymorphisms may help to detect molecular mechanisms that are causally related to the disease process.

Aim: To examine associations between the common genetic variants in candidate inflammatory cytokine genes and NEC in preterm infants.

Methods: Multi-centre case-control and genetic association study. DNA samples were collected from 50 preterm infants with NEC and 50 controls matched for gestational age and ethnic group recruited to a multicentre case-control study. Ten candidate single-nucleotide polymorphisms in cytokines previously associated with infectious or inflammatory diseases were genotyped. The findings were included in random-effects metaanalyses with data from previous genetic association studies.

Results: All allele distributions were in Hardy-Weinberg equilibrium. None of the studied cytokine polymorphisms was significantly associated with NEC. Four previous genetic association studies of cytokine polymorphisms and NEC in preterm infants were found. Meta-analyses were possible for several single-nucleotide polymorphisms. These increased the precision of the estimates of effect size but did not reveal any significant associations. Conclusions: The available data are not consistent with more than modest associations between these candidate cytokine variant alleles and NEC in preterm infants. Data from future association studies of these polymorphisms may be added to the meta-analyses to obtain more precise estimates of effects sizes.

Necrotising enterocolitis (NEC) is a major cause of death and disability in preterm infants but its pathogenesis is incompletely understood. Gut immaturity and sub-optimal gut perfusion, exacerbated by enteral feeding, may be important. Additional factors, including enteric or systemic infection, may then precipitate a cascade of inflammatory events leading to the clinical and pathological end point of NEC. ${ }^{1}$

Evidence exists for the involvement of several host inflammatory mediators in the final common pathway leading to NEC. Plasma concentrations and tissue expression of the proinflammatory cytokines, tumour necrosis factor (TNF), interleukin (IL)-1 $\beta$, IL6, IL8 and IL18, are increased in infants with NEC. ${ }^{2-4}$ Proinflammatory effects are modulated by receptor antagonists and regulation of receptors as well as by the effects of antiinflammatory cytokine cascades, principally

\section{What is already known on this topic}

- Inflammatory cytokine cascades may play a key role in the pathogenesis of necrotising enterocolitis (NEC) in preterm infants.

- Genetic association studies may help to distinguish causal molecular mechanisms from epiphenomena.

\section{What this study adds}

None of the candidate cytokine polymorphisms so far studied is significantly associated with NEC.

IL10. ${ }^{5}$ Studies using animal models have suggested that modulating the inflammatory cytokine cascade may be a beneficial adjunctive strategy for treating preterm infants with NEC. ${ }^{7-9}$

In investigating the contribution of these complex cytokine cascades to the pathogenesis of NEC, it is difficult to distinguish molecular mechanisms that are causal from those that are epiphenomena of the disease process. Raised plasma and tissue concentrations of inflammatory mediators may be a consequence, rather than the cause, of the disease. An alternative strategy that obviates these problems is to examine whether the risk of NEC is associated with genetic factors that regulate cytokine production or function. This approach has been used to study the role of inflammatory mediators in a number of diseases associated with preterm birth, including NEC. ${ }^{10-12}$

Here we have examined associations between variants in candidate cytokine genes with susceptibility to NEC in preterm infants recruited to a multi-centre case-control study. We focused on common single-nucleotide polymorphisms (SNPs) that are of likely or proved functional significance, or have plausible disease associations described previously. As genetic association studies in this field are often limited by small sample sizes and are underpowered to exclude modest associations, where possible, we have quantitatively synthesised the study findings with data from other studies in order to provide a more precise estimate of the effect size. ${ }^{13}$

\section{METHODS}

A case-control study of NEC in preterm infants was conducted in 10 neonatal units in the north of Britain between January 2004 and December 2005. 
Table 1 Location of candidate single-nucleotide polymorphism (SNP) relative to transcription start site

\begin{tabular}{|c|c|c|}
\hline Cytokine & $\begin{array}{l}\text { SNP position } \\
\text { (major/minor allele) }\end{array}$ & Putative effect of minor allele \\
\hline TNF & $-238(G / A)$ & Increased transcription ${ }^{15 *}$ \\
\hline TNF & $-308(\mathrm{G} / \mathrm{A})$ & Increased transcription ${ }^{15} 16 *$ \\
\hline IL1 $\beta$ & $-31(\mathrm{~T} / \mathrm{C})$ & Decreased transcription ${ }^{17}$ \\
\hline IL1 $\beta$ & $-511(\mathrm{C} / \mathrm{T})$ & Increased transcription ${ }^{17}$ \\
\hline IL4 receptor $\alpha$ & $+1902(\mathrm{G} / \mathrm{A})$ & Enhanced signalling $^{18}$ \\
\hline IL6 & $-174(\mathrm{G} / \mathrm{C})$ & Increased production ${ }^{19}$ \\
\hline IL8 & $-251(T / A)$ & Increased production ${ }^{20}$ \\
\hline IL10 & $-1082(G / A)$ & Reduced transcription ${ }^{21}$ \\
\hline IL18 & $-137(\mathrm{G} / \mathrm{C})$ & Reduced transcription ${ }^{22}$ \\
\hline IL18 & $-607(\mathrm{C} / \mathrm{A})$ & Reduced transcription ${ }^{22}$ \\
\hline
\end{tabular}

${ }^{*}$ Cell/stimulus specific.

$\mathrm{IL}$, interleukin; TNF, tumour necrosis factor.

Briefly, cases were preterm infants with NEC diagnosed using modified Bell criteria or at laparotomy or autopsy examination. Controls were infants who had not developed NEC by 34 weeks' postmenstrual age. Cases and controls were frequency-matched for gestational age at birth. More details of the methods are published elsewhere. ${ }^{14}$ The Northern \& Yorkshire multi-centre research ethics committee approved the study.

A dried blood sample from each infant was collected on filter paper (Whatman FTA, Whatman International, Maidstone, Kent, UK). DNA was extracted using the REDExtract-N-Amp Blood PCR kit (Sigma Chemicals, Poole, Dorset, UK). The relevant sequences were amplified by PCR, and the products sequenced in an automated sequencer using a standard SNaPshot run setup (see online supplement for PCR SNP primer sequences and PCR run conditions). Alleles were assigned with the ABI GeneMapper software and rechecked manually. Data were analysed combining individuals homozygous and heterozygous for the variant allele into a single exposure class.

\section{Meta-analysis}

Medline (1966-2007) and EMBASE (1980-2007) were searched for genetic association studies using the following text words and $\mathrm{MeSH}$ terms: [Enterocolitis, Necrotizing OR necrotising enterocolitis OR NEC] AND [Polymorphism, Genetic OR Cytokines/genetics]. References in previous reviews and studies
Table 2 Variant cytokine genotypes in cases and controls

\begin{tabular}{lrrl}
\hline Allele & \multicolumn{1}{c}{ Cases } & Controls & OR (95\% CI) \\
\hline TNF $(-308 A)$ & $19(38 \%)$ & $17(34 \%)$ & $1.19(0.53$ to 2.69$)$ \\
TNF (-238A) & $6(12 \%)$ & $9(18 \%)$ & $0.62(0.20$ to 1.90$)$ \\
IL1 (-31G) & $28(56 \%)$ & $33(66 \%)$ & $0.66(0.29$ to 1.47$)$ \\
IL1 (-511T) & $30(60 \%)$ & $33(66 \%)$ & $0.77(0.24$ to 1.74$)$ \\
IL4R (+1902G) & $15(30 \%)$ & $13(26 \%)$ & $1.22(0.51$ to 2.93$)$ \\
IL6 (-174C) & $37(74 \%)$ & $34(68 \%)$ & $1.34(0.56$ to 3.19$)$ \\
IL8 (-251A) & $36(72 \%)$ & $40(80 \%)$ & $0.64(0.25$ to 1.63$)$ \\
IL10 (-1082G) & $39(78 \%)$ & $38(76 \%)$ & $1.12(0.44$ to 2.84$)$ \\
IL18 (-137C) & $20(40 \%)$ & $25(50 \%)$ & $0.67(0.30$ to 1.47$)$ \\
IL18 (-607A) & $31(62 \%)$ & $30(60 \%)$ & $1.09(0.49$ to 2.43$)$ \\
\hline
\end{tabular}

IL, interleukin; IL4R, interleukin 4 receptor; TNF, tumour necrosis factor.

were examined. Abstracts presented at the Society for Pediatric Research and European Society for Pediatric Research between 1995 and 2006 were searched.

For each potentially eligible study, information on setting, design, inclusion/exclusion criteria and genotyping method was extracted. Study investigators were contacted to obtain additional information if necessary. Case-control and cohort studies were eligible for inclusion provided that (a) NEC was defined using standard criteria (Bell staging or modifications), (b) the enrolment of participants was not made on the basis of prior knowledge of genotype, (c) genotyping had been blinded to clinical status, (d) the study reported the ethnic ancestry of participants, (e) the reported genotype distributions were in Hardy-Weinberg equilibrium, and $(f)$ the report provided data sufficient to calculate an odds ratio (OR). Included data were synthesised in random-effects meta-analyses - that is, with no a priori assumption of effect homogeneity-using RevMan software (version 4.2). Heterogeneity was assessed using the $\chi^{2}$ test $(p<0.1$ considered significant).

\section{RESULTS}

\section{Genetic association study}

Ten polymorphisms were genotyped in 50 cases and 50 matched controls (table 1). Allele distribution was in Hardy-Weinberg equilibrium for all polymorphisms. The proportion of infants with the variant allele did not differ significantly between cases and controls for any of the comparisons (table 2). The findings did not change when analysis was restricted to infants with stage $2 / 3$ NEC $(n=38)$.

Table 3 Cytokine genetic association studies in NEC

\begin{tabular}{|c|c|c|c|c|}
\hline Reference & $\begin{array}{l}\text { Country and } \\
\text { predominant } \\
\text { ethnic groups }\end{array}$ & Participants & Design (cases/controls) & Alleles studied \\
\hline $23-25$ & Hungary/Caucasian & $\begin{array}{l}\mathrm{BW}<1500 \mathrm{~g} \\
\mathrm{NEC}=\text { Bell stage } 1-3\end{array}$ & Case-control (46/90) & $\begin{array}{l}\text { TNF }(-308 \mathrm{~A}) \\
\text { TNF }(-238 \mathrm{~A}) \\
\text { IL4R }(+1902 \mathrm{G}) \\
\text { IL6 }(-174 \mathrm{C}) \\
\text { IL10 }(-1082 \mathrm{G})\end{array}$ \\
\hline 26 & $\begin{array}{l}\text { USA/Caucasian and } \\
\text { African-American }\end{array}$ & $\begin{array}{l}\mathrm{BW}<1250 \mathrm{~g} \\
\mathrm{NEC}=\text { Bell stage } 1-3\end{array}$ & Prospective cohort (39/102) & $\begin{array}{l}\operatorname{IL18}(-607 \mathrm{~A}) \\
\operatorname{TNF}(-308 \mathrm{~A}) \\
\operatorname{TNF}(-238 \mathrm{~A})\end{array}$ \\
\hline 27,28 & $\begin{array}{l}\text { USA/Caucasian and } \\
\text { African-American }\end{array}$ & $\begin{array}{l}\mathrm{BW}<1500 \mathrm{~g} \\
\text { Mechanically ventilated }\end{array}$ & Retrospective cohort (26/262) & $\begin{array}{l}\text { TNF }(-308 A) \\
\text { IL6 }(-174 C)\end{array}$ \\
\hline 29 & Germany/Caucasian & $\begin{array}{l}\mathrm{NEC}=\text { Bell stage } 1-3 \\
\mathrm{GA}<32 \text { weeks } \\
\mathrm{NEC}=\text { Bell stage } 1-3\end{array}$ & Retrospective cohort $(9 / 64)$ & $\begin{array}{l}\operatorname{IL10}(-1082 \mathrm{G}) \\
\text { TNF }(-308 \mathrm{~A}) \\
\text { IL10 }(-1082 \mathrm{G})\end{array}$ \\
\hline
\end{tabular}

BW, birth weight; GA, gestational age; IL, interleukin; IL4R, interleukin 4 receptor; NEC necrotising enterocolitis; TNF, tumour necrosis factor. 
Downloaded from fn.bmj.com on 13 April 2009

Figure 1 Meta-analyses (random effects) of genetic association studies. IL, interleukin; TNF, tumour necrosis factor. a, African-American; b, Caucasian.

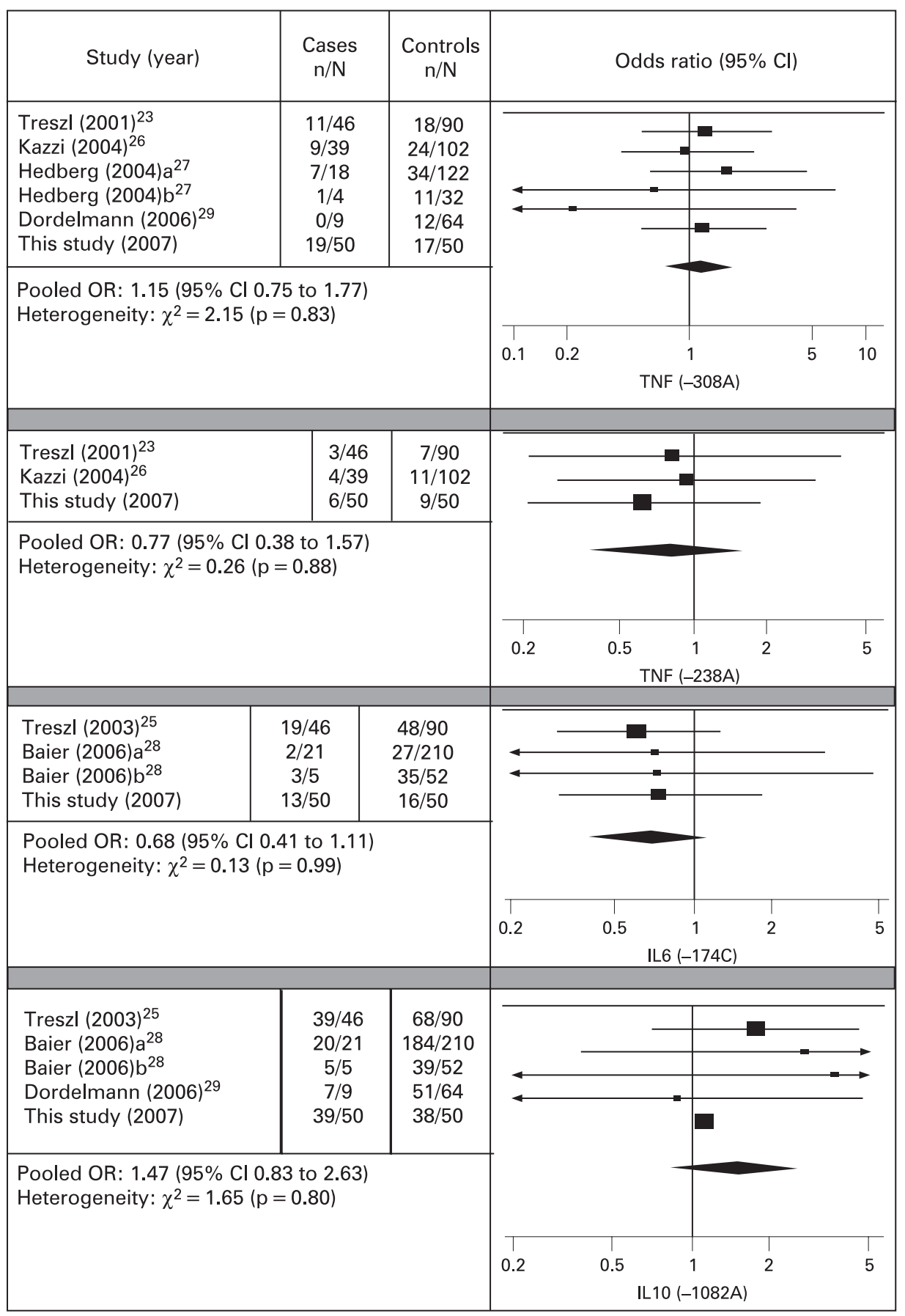

\section{Systematic literature search}

Four genetic association studies of cytokine polymorphisms and $\mathrm{NEC}$ in preterm infants were found (table 3). ${ }^{23-29}$

\section{Meta-analyses}

TNF $(-308 \mathrm{~A}), \operatorname{TNF}(-238 \mathrm{~A}), \operatorname{IL} 6(-174 \mathrm{C})$ and IL10 $(-1082 \mathrm{~A})$

Random-effects meta-analyses of data from this study with those from previous studies did not reveal any significant differences (fig 1). None of the meta-analyses revealed significant heterogeneity.

\section{IL4 receptor (+1902G)}

The only previous study to have examined the association of the IL4 receptor (+1902G) with NEC reported that the variant allele was significantly less common in cases than controls (cases 10/ 46; controls 37/90; OR 0.40 (95\% CI 0.18 to 0.90$)$ ). ${ }^{25}$ We did not find any significant difference in the present study (cases 15/50; controls 13/50; OR 1.22 (95\% CI 0.51 to 2.93)). Meta-analysis of combined data did not find a significant association (pooled OR 0.66 (95\% CI 0.37 to 1.18$)$ ).

\section{IL18 (-607A)}

One study (in a post hoc analysis) reported that the proportion of infants homozygous for the IL18 (-607A) allele (AA genotype) was significantly higher in infants with stage 3 NEC (cases 4/8; controls 7/90; OR 11.9 (95\% CI 2.4 to 57.9)). ${ }^{24}$ We did not find a significant difference in the present study (cases 1/7; controls 7/50; OR 0.77 (95\% CI 0.08 to 7.12)). When 
these data were meta-analysed, the association was not statistically significant (pooled OR 3.36 (95\% CI 0.21 to 53.6)).

\section{DISCUSSION}

The available data suggest that these common cytokine genetic polymorphisms are not strongly associated with the risk of NEC in preterm infants. In most cases, the estimates of effect size suggest that modest effects have not been missed. For some associations, use of meta-analytical techniques commonly used for synthesising the findings of controlled trials allowed us to increase the precision of the estimates. Meta-analyses were possible because the studies recruited broadly similar populations of infants using standard case definitions of NEC as inclusion criteria. Controls were selected from ethnically similar populations, or data provided to allow stratified analysis by ethnic background to account for the potential confounding effect of population admixture. ${ }^{13}$ Although data were pooled from different study designs, we did not find statistical evidence of heterogeneity in the meta-analyses, suggesting that these estimates are reliable.

The TNF promoter polymorphisms (-308A and -238A) have been the most commonly studied cytokine gene variants. Our findings are consistent with those of three previous studies, which did not detect any significant associations with NEC. ${ }^{23} 24$ Although the estimates of effect size from each individual study were wide, meta-analysis of all of these data suggests that, if any associations do exist, they are likely to be very modest. This lack of association does not rule out the possibility that TNF and other proinflammatory cytokines are important in the pathogenesis of NEC in preterm infants. True associations may exist but with very modest effect sizes too small to be excluded by the available data. Alternatively, it may be that the candidate polymorphisms that we have studied are not directly involved in gene regulation, or that any functional effect is dependent on the haplotypic background for which neither we, nor others, have data.

Meta-analysis of association studies also suggests that the common IL6 (-174C) SNP is very unlikely to increase susceptibility to NEC. However, the lower bound of the 95\% CI for the OR was consistent with a modest protective effect (halving of odds). Evidence exists that this polymorphism increases IL6 production in neonatal lymphocytes stimulated with lipopolysaccharide ${ }^{17}$ Carriage of the variant is associated with protection against invasive infection in preterm infants, presumably by enhancing the immune response. ${ }^{30}$ Although it is biologically plausible that a polymorphism that enhances the inflammatory response may increase the risk (or severity) of NEC, another possibility is that such a polymorphism may reduce the risk of NEC by preventing enteric or systemic infections that trigger the inflammatory cascade. Similarly, the IL10 (-1082A) variant has been associated with an increase in susceptibility to late-onset invasive infection in preterm infants. ${ }^{28}$ Meta-analysis of data from five studies did not reveal a significant association with NEC, but the upper bound of the 95\% CI of the OR (2.6) does not exclude a modest effect size. Data from future association studies may be added to this meta-analysis to increase the precision of these estimates of effect size.

Only two studies have previously reported significant associations between cytokine polymorphisms and NEC. Treszl and colleagues found that genetic variation in the IL4 receptor (+1902G) was associated with a lower risk of NEC. ${ }^{25}$ The investigators suggested that the enhanced production of IL4 protected the immature gastrointestinal tract from inflammation and that screening for this allele would allow targeted surveillance and intervention to prevent NEC in at-risk infants. In the present study, and on meta-analysis of data from both studies, we did not find a significant association, suggesting that such an approach is not justified at present.

The same investigators reported an association between homozygosity of the IL18 (-607A) allele with stage 3 NEC. ${ }^{24}$ However, this association appears to have been the result of a post hoc subgroup analysis, and therefore may have been spurious. We did not detect a similar effect, and meta-analysing the data suggests there to be no significant association with NEC. These findings support the need to confirm reports of genetic associations in independent populations, particularly if the first reported effect size is modest, derived from a post hoc or subgroup analysis, and was detected as part of a larger association study where multiple comparisons were made. ${ }^{13}$

Genetic association studies may also be useful in examining the role of other inflammatory mediators in the pathogenesis of NEC. Candidates for further investigation include plateletactivating factor (a phospholipid with complex biological functions that may be a key mediator in the process leading to NEC), cyclo-oxygenase-2, and various forms of nitric oxide synthase that mediate the downstream vascular effects of the inflammatory cascade. ${ }^{1}$ Such studies should aim to study similar populations of infants (using standard case definitions) and use measures to avoid confounding, particularly ethnic heterogeneity. The use of family-based studies, which allow multiple genetic markers to be examined without the possibility of confounding due to population admixture, may be particularly suitable for investigating complex diseases of preterm infants.

Acknowledgements: We thank the principal investigators of the cited genetic association studies for providing further data for inclusion in the meta-analyses.

Funding: The study was funded by Tenovus (Scotland). The funder had no role in the collection, analysis and interpretation of data, or in the writing of the report and the decision to submit the paper for publication. The National Perinatal Epidemiology Unit receives funding from the Department of Health. The views expressed in this publication are those of the authors and not necessarily those of the Department of Health.

Competing interests: None.

\section{REFERENCES}

1. Martin CR, Walker WA. Intestinal immune defences and the inflammatory response in necrotising enterocolitis. Semin Fetal Neonatal Med 2006;11:369-77.

2. Harris MC, Costarino AT Jr, Sullivan JS, et al. Cytokine elevations in critically ill infants with sepsis and necrotizing enterocolitis. J Pediatr 1994;124:105-11.

3. Viscardi RM, Lyon NH, Sun CC, et al. Inflammatory cytokine mRNAs in surgical specimens of necrotizing enterocolitis and normal newborn intestine. Pediatr Pathol Lab Med 1997;17:547-59

4. Halpern MD, Holubec H, Dominguez JA, et al. Up-regulation of IL-18 and IL-12 in the ileum of neonatal rats with necrotizing enterocolitis. Pediatr Res 2002:51:733-9.

5. Edelson MB, Bagwell CE, Rozycki HJ. Circulating pro- and counterinflammatory cytokine levels and severity in necrotizing enterocolitis. Pediatrics 1999;103:766-71.

6. $\quad \mathbf{N g}$ PC, Li K, Wong RP, et al. Proinflammatory and anti-inflammatory cytokine responses in preterm infants with systemic infections. Arch Dis Child Fetal Neonatal Ed 2003;88:F209-13.

7. Travadi J, Patole S, Charles A, et al. Pentoxifylline reduces the incidence and severity of necrotizing enterocolitis in a neonatal rat model. Pediatr Res 2006;60:185-9.

8. Halpern MD, Clark JA, Saunders TA, et al. Reduction of experimental necrotizing enterocolitis with anti-TNF-alpha. Am J Physiol Gastrointest Liver Physiol 2006;290:G757-64.

9. Ozturk H, Dokucu Al, Ogun C, et al. Protective effects of recombinant human interleukin-10 on intestines of hypoxia-induced necrotizing enterocolitis in immature rats. J Pediatr Surg 2002;37:1330-3.

10. Lin HC, Tsai FJ, Tsai CH, et al. Cytokine polymorphisms and chronic lung disease in small preterm infants. Arch Dis Child Fetal Neonatal Ed 2005;90:F93-4.

11. Bokodi G, Derzbach L, Banyasz I, et al. Association of interferon gamma T+874A and interleukin 12 p40 promoter CTCTAA/GC polymorphism with the need for respiratory support and perinatal complications in low birthweight neonates. Arch Dis Child Fetal Neonatal Ed 2007:92:F25-9.

12. Harding D. Impact of common genetic variation on neonatal disease and outcome. Arch Dis Child Fetal Neonatal Ed 2007;92:F408-13. 
13. Hanchard NA. Genetic susceptibility and single-nucleotide polymorphisms. Semin Fetal Neonatal Med 2005;10:283-9.

14. Henderson G, Craig S, Brocklehurst P, et al. Enteral feeding regimens and necrotising enterocolitis in preterm infants: multi-centre case-control study. Arch Dis Child Fetal Neonatal Ed 2008;93:in press.

15. Bayley JP, de Rooij H, van den Elsen PJ, et al. Functional analysis of linker-scan mutants spanning the $-376,-308,-244$, and -238 polymorphic sites of the TNFalpha promoter. Cytokine 2001;14:316-23.

16. Wilson AG, Symons JA, McDowell TL, et al. Effects of a polymorphism in the human tumor necrosis factor alpha promoter on transcriptional activation. Proc Nat/ Acad Sci USA 1997;94:3195-9.

17. Chen $\mathbf{H}$, Wilkins $L M$, Aziz $N$, et al. Single nucleotide polymorphisms in the human interleukin-1B gene affect transcription according to haplotype context. Hum Mol Genet 2006;15:519-29.

18. Kruse S, Japha T, Tedner M, et al. The polymorphisms S503P and 0576R in the interleukin-4 receptor alpha gene are associated with atopy and influence the signal transduction. Immunology 1999;96:365-71.

19. Kilpinen S, Hulkkonen J, Wang XY, et al. The promoter polymorphism of the interleukin-6 gene regulates interleukin-6 production in neonates but not in adults. Eur Cytokine Netw 2001;12:62-8.

20. Hull J, Thomson A, Kwiatkowski D. Association of respiratory syncytial virus bronchiolitis with the interleukin 8 gene region in UK families. Thorax 2000:55:1023-7.

21. Turner DM, Williams DM, Sankaran D, et al. An investigation of polymorphism in the interleukin-10 gene promoter. Eur J Immunogenet 1997;24:1-8.
22. Giedraitis $\mathbf{V}, \mathrm{He} B$, Huang $W X$, et al. Cloning and mutation analysis of the human IL18 promoter: a possible role of polymorphisms in expression regulation. J Neuroimmunol 2001:112:146-52.

23. Treszl A, Kocsis I, Szathmari M, et al. Genetic variants of the tumour necrosis factoralpha promoter gene do not influence the development of necrotizing enterocolitis. Acta Paediatr 2001;90:1182-5.

24. Heninger $\mathbf{E}$, Treszl A, Kocsis I, et al. Genetic variants of the interleukin-18 promoter region $(-607)$ influence the course of necrotising enterocolitis in very low birth weight neonates. Eur J Pediatr 2002;161:410-11.

25. Treszl A, Heninger E, Kalman A, et al. Lower prevalence of IL-4 receptor alpha-chain gene $\mathrm{G}$ variant in very-low-birth-weight infants with necrotizing enterocolitis. J Pediatr Surg 2003;38:1374-8.

26. Kazzi SNJ, Kim 0, Quasney MH. Do alleles of tumour necrosis factor gene affect the susceptibility and/or severity of necrotizing enterocolitis? Pediatr Res 2004;55:2754.

27. Hedberg CL, Adcock K, Martin J, et al. Tumor necrosis factor alpha- -308 polymorphism associated with increased sepsis mortality in ventilated very low birth weight infants. Pediatr Infect Dis J 2004;23:424-8.

28. Baier RJ, Loggins J, Yanamandra K. IL-10, IL-6 and CD14 polymorphisms and sepsis outcome in ventilated very low birth weight infants. BMC Med 2006;4:10.

29. Dordelmann M, Kerk J, Dressler F, et al. Interleukin-10 high producer allele and ultrasound-defined periventricular white matter abnormalities in preterm infants: a preliminary study. Neuropediatrics 2006;37:130-6.

30. Harding D, Dhamrait S, Millar A, et al. Is interleukin-6 -174 genotype associated with the development of septicemia in preterm infants? Pediatrics 2003;112:800-3.

Stay a step ahead with Online First

We publish all our original articles online before they appear in a print issue. This means that the latest clinical research papers go straight from acceptance to your browser, keeping you at the cutting edge of medicine. We update the site weekly so that it remains as topical as possible. Follow the Online First link on the home page and read the latest research. 